\title{
Computer-aided Simulation Model of Stator Groundwall Insulation of Induction Motor based on Current Park's Vector Approach
}

\author{
Amit J Modak \\ Research Student \\ Electrical Engineering \\ Walchand College of Engineering, Sangli
}

\author{
Dr. H.P. Inamdar \\ Professor \\ Electrical Engineering \\ Rajarambapu Institute of Technology, Sakhrale
}

\begin{abstract}
Modeling and simulation studies published in the literature have shown that the stator winding faults are one of the major causes of induction motor failure. The spectrum analysis and AI-based fault diagnosis techniques were introduced to detect such faults at the early stage. However, there is not much mention about the deterioration of stator winding on account of degradation of stator groundwall insulation. This paper investigates the methodology to simulate the percentage of degradation related with deterioration of stator groundwall insulation of induction motor.

A design of computer based simulation model to generate the stator current data pattern for the simulation of degree of degradation of stator groundwall insulation based on Current Park's vector approach [1] is presented. The generated stator current data pattern can be further applied to any suitable artificial neural network classifier for the artificial intelligence based fault diagnosis process. The need for the evaluation, based on computer simulation is also indicated.
\end{abstract}

\section{General Terms}

Machine Intelligence, Diagnostic and Decision Supporting System

\section{Keywords}

Current Park's Transformation, induction motor, artificial intelligence (AI) techniques, Groundwall Insulation

\section{INTRODUCTION}

In the context of fault diagnosis based on spectrum analysis and AI-techniques, various stator winding faults were verified in the previous work [1-4]. These stator winding faults at the initial phase are in un-detected state. These faults over a period of time develop into major form to cause the sudden failure of the machine [3]. Several diagnostic media and techniques are suggested in the literature in order to diagnose stator winding faults so as to allow for carefully planned repair actions [5, 6]. The Park's Vector Approach has also been successfully applied in the diagnosis of inter-turn short circuit in stator winding [7] and air gap eccentricity [8] in three-phase induction motors. The effect of insulation degradation on account of inter-turn short circuit based on extended parks vector approach and spectrum analysis has been reported in the previous literature [3].The effect of insulation degradation due to inter-turn short circuit on stator structure and rotor bearings in the form of their vibrations has been reported in the literature [9]. The unbalance in the stator current, on account of inter-turn short circuit produces the stator vibrations. As shown in the Figure 1; the concept of the presence of shunt resistance $\left(\mathrm{R}_{\mathrm{sh}}\right)$ distributed only across the particular coil in a phase is introduced in view of inter-turn short circuit in the coil in the earlier investigation [9].

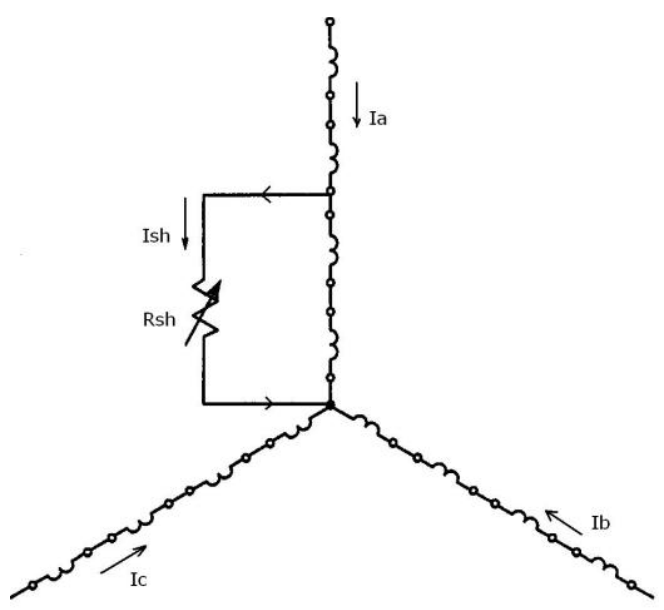

Figure 1. Stator Winding with Simulated Deterioration of Inter-turn Short Circuit

However, there is no information about the investigation in the context of degree of degradation of stator groundwall insulation. The objective of this paper is to introduce the method, which decides an extent of degradation of groundwall insulation of respective phases of stator winding. The insulation sheets between the slots and coils and on the enameled wires and between the turns in the coil are consists of different classes of insulation material. The choice depends on the maximum temperature rise permissible for each class. For each class of insulation material there exist limiting temperatures beyond which deterioration sets in and progresses rapidly. The degradation of groundwall insulation of the respective phase results in the reduction of resistance to the thermal conductivity. This results into higher heat transfer from the surface of the stator windings to the remaining part of structure. The interpretation of higher heat transfer is that the motor is subjected to extra load. Hence, motor draws more current as compared to what it would have drawn had the insulation not degraded. The increase in current is interpreted as reduction in the steady-state equivalent resistance of motor referred to stator. This is based on the interpretation of the presence of shunt resistance $\left(\mathrm{R}_{\mathrm{sh}}\right)$ distributed across the entire phase as represented in the Figure 2. The degree of degradation of stator groundwall insulation is estimated on the basis of unbalance in stator phase currents. 
Although there is no experimental data to indicate the time delay between inter-turn and groundwall insulation failure, it is probable that the transition between two states is not instantaneous. Therefore, like in case of inter-turn short circuit, early detection of phase short circuit during motor operation would eliminate subsequent damage to coils of the respective phase and stator core. This is useful from the point of view of repair cost and motor outage time. This leads to cost effective condition based maintenance.

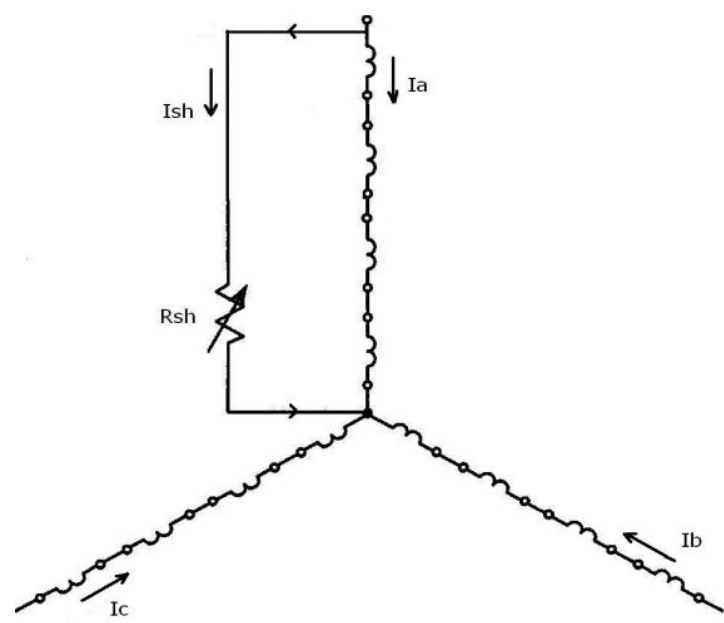

Figure 2. Stator Winding with Simulated Deterioration of Groundwall Insulation

\section{FORMULATION OF WORK AND SUGGESTED APPROACH}

In this investigation in view of forgoing detailed justification, a simple simulation model for the detection of degradation of stator winding groundwall insulation of cage-rotor induction motor is developed. For the induction motor of particular make, type and the frame size of suitable rating employed for particular application in an industry, it is probable that the status of degradation of stator groundwall insulation varies over considerable finite range. The finite range extends from certain minimum to permissible maximum value. The variation in the range of degradation particularly depends on several factors such as the time period over which motors are in use and the operating conditions. On experimental basis it is not feasible to collect the large set of unbalance stator current data pattern, which would model the entire range of degradation for the motor in use in particular industry. Further, in neural network based AI-technique, a large set of data pattern availability is required for the development of diagnostic model to detect the degradation of stator groundwall insulation. This is essential from the point of view of optimal design and efficient performance of the neural network classifier. Hence in this work it is decided to formulate a simulation model, which will provide the unbalanced stator current data patterns for modeling the entire range of 5\% to $95 \%$ of degradation of stator groundwall insulation.

The steps to establish aforesaid model for modeling degradation of stator groundwall insulation of cage-rotor induction motor are as under- a) Determination of machine parameters for machine under test.

b) The computation of steady state performance of induction motor in machine variable form under minimum mechanical load condition.

c) Evaluation of maximum and minimum values of shunt resistances across the real part of equivalent steady- state motor impedance per phase referred to stator side at stator frequency under minimum mechanical load condition.

d) The computation of the numerical values of number of shunt resistances between maximum and minimum values, which are simulating different state of degradation of stator groundwall insulation.

e) Determination of various combinations of equivalent stator impedances which simulate the effect of percentage degradation of stator groundwall insulation.

f) Estimation of stator current per phase for all combinations established in step (e) as given above.

g) Development of current parks transformation model for computation of direct-axis and quadrature axis current components of three-phase stator currents with frame of reference fixed to stator.

h) Computations of parks current vector patterns for all combinations established in step (g) as given above.

i) Classification of all combinations of parks vector patterns established in step (h) as given above in accordance with the percentage of degradation of stator groundwall insulation.

The induction motor of particular make, type and the frame-size of suitable rating employed for particular application in an industry usually operate under variable load condition. In general, the motor is operating with the presence of many recipient faults, which are observable at corresponding frequencies in stator current spectrum [10-11]. These include the stator winding faults due to several causes like inter-turn short circuit etc; but other than the fault of stator groundwall insulation degradation. The fault with the stator groundwall insulation degradation would appear at supply frequency. In the spectrum the amplitude of current corresponding to supply frequency has 'two' components; one due to actual load and other due to the stator groundwall insulation degradation. In order to fetch the current component due to stator groundwall insulation degradation it is therefore essential to eliminate the current component due to load. Hence, it is obvious that the motor is to be operated at minimum mechanical load to ascertain the degree of degradation of stator groundwall insulation.

\section{COMPUTER SIMULATION}

Simulation analysis was conducted on three-phase; $7.5-\mathrm{kW}$, star (Y)-connected, six-pole, induction motor. The details of simulation model for the evaluation of degradation of stator winding groundwall insulation is as under- 


\subsection{Measurement of Induction Motor Machine Parameters}

The measurement of motor parameters is based on steady-state equivalent circuit of induction motor with the rotor at stator frequency as shown in the Figure 3. The stator resistance test, noload test and locked rotor tests were conducted to measure the following motor parameters as shown below-

$\mathrm{R}_{\mathrm{s}}=$ Stator resistance per phase $=0.1134 \Omega$.

$\mathrm{R}_{\mathrm{r}}=$ Rotor resistance per phase referred to stator $=0.6808 \Omega$

$\mathrm{R}_{\mathrm{c}}=$ Core-loss resistance per phase $=235.00 \Omega$

$\mathrm{X}_{\mathrm{ls}}=$ Stator leakage-reactance per phase $=0.16 \Omega$.

$\mathrm{X}_{\mathrm{lr}}=$ Rotor leakage reactance per phase referred to stator $=0.16 \Omega$.

$\mathrm{X}_{\mathrm{m}}=$ Magnetizing mutual-reactance per phase $=75.00 \Omega$.

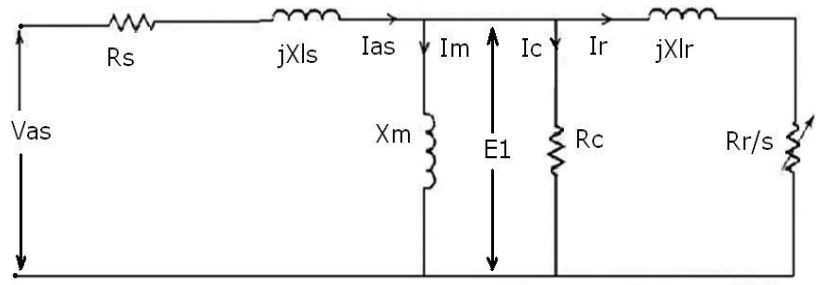

Figure 3. Steady-State Equivalent Circuit with Rotor at Stator Frequency

The measurement tests were performed at input power supply frequency of ' 50 ' $\mathrm{Hz}$ and rated operating line voltage of ' 415.0 'volts. The stator winding is star (Y) connected with number of poles as ' 6 '.

$\mathrm{P}=$ Number of poles in machine $=6$

$\mathrm{F}_{\mathrm{s}}=$ Stator input power supply line frequency $=50 \mathrm{~Hz}$.

$\mathrm{V}_{\mathrm{ll}}=$ Line to line stator voltage $=415$ Volts .

$\mathrm{V}_{\mathrm{as}}=$ Stator voltage per phase $=239.60$ Volts

\subsection{Performance Assessment of Motor by Steady-State Equivalent Circuit Simulation}

The computer simulation of steady-state equivalent circuit of induction motor with rotor at stator frequency is done on Matlab. The measured machine parameters are used to assess the performance of cage-rotor induction motor at minimum mechanical load condition in the machine variable form. The minimum mechanical load condition is realized by decoupling the mechanical load from the shaft of motor. The operating speed of motor under minimum load condition is observed. The corresponding minimum slip value (s_nl) is used in simulation model to assess the steady state performance of motor at minimum load condition. The rotor operating speed in rpm under minimum mechanical load condition and its corresponding minimum slip value is as given in equation (1)

$$
\mathrm{Nr} \_n l=987.0 \text { rpm; s_nl= } 0.0133
$$

The computations of motor variables of cage-rotor induction motor under test in machine variable form operating at minimum mechanical load are listed in Table 1.
Table 1. Induction Motor Variables in Machine Variable Form at Minimum Mechanical Load

\begin{tabular}{|c|c|}
\hline Motor Variable & Operating Values \\
\hline Zseq1_im_nl $(\Omega)$ & 36.7698 \\
\hline Ias_nl $($ Amps.) & 6.5162 \\
\hline Te_nl $(\mathrm{N}-\mathrm{m})$ & 31.8675 \\
\hline per_eff_nl & 80.7546 \\
\hline pf_nl & 0.8705 \\
\hline
\end{tabular}

Where, Zseq1_im_nl=Absolute value of equivalent motorimpedance per phase referred to stator at minimum mechanical load,

Ias_nl $=$ Absolute value of stator current per phase at minimum load,

Te_nl=Air-gap/Electromagnetic torque at minimum mechanical load in N-m,

per_eff_nl= Percentage efficiency of motor at minimum mechanical load,

pf_nl= Operating power-factor of motor at minimum mechanical load.

The absolute value of stator current per phase referred from Table 1 ; above and as represented in equation (2) for motor operation at minimum mechanical load is the lowest observed value of balanced three-phase stator current.

Ias_nl $=$ Absolute value of stator current per phase at minimum mechanical load $=6.5162$ Amps.

This current is drawn from the balanced three-phase power supply voltage of ' 415.0 ' volts and contain fundamental line frequency component of ' 50 ' $\mathrm{Hz}$ only. The absence of any other frequency components confirms that the motor is healthy with very good state of stator groundwall insulation and also free from rest of the other faults. Hence, it is selected as a frame of reference to represent zero percent $(0 \%)$ state of degradation of stator groundwall insulation of cage-rotor induction motor. With respect to this frame of reference, the unbalance stator current data patterns are compared to determine the percentage of degradation of stator groundwall insulation. The corresponding absolute value of stator-impedance per phase at minimum mechanical load condition based on simulation results as shown in Table 1 , is given in equation (3)

Zseq1_im_nl=Absolute value of equivalent stator impedance per phase at minimum load $=36.7698 \Omega$

\subsection{Computation of Motor Parameters between Minimum and Maximum Percentage of Degradation of Stator Groundwall Insulation}

In most of the commercially available induction motors, coils are insulated from one another in the slots as well as in the end winding region. Therefore, the highest probability for the occurrence of inter-turn short circuit is between the turns in the same coil. Here, it is assumed that the inter-turn short circuit exists in between the two turns of the same coil. As a consequence of the inter-turn short circuit, the MMF of the phase winding in which inter-turn short circuit exists changes, as does the mutual 
inductance between that phase and all other circuits in the machine. Thus, under the presence of an inter-turn short circuit, the winding function, which is MMF per unit current of the injured phase, is changed. As a consequence of such fault, selfinductance and resistance of the particular phase are changed as well as the mutual inductance between this phase and all other circuits in the machine. However, the highest probability for the occurrence of phase short circuit due to groundwall insulation degradation is in the end winding region. In this case the variation in the self -inductance of injured phase and the mutual inductance between other phases is very less as compared to the variation in the per phase resistance. Any level of percentage of degradation for particular phase is interpreted as reduction in the steady-state equivalent resistance of phase referred to stator.

It is reasonable to assume five percent $(5 \%)$ reduction in real part of equivalent steady-state stator impedance per phase at minimum mechanical load as given in equation (3) to simulate some finite minimum state of degradation of stator groundwall insulation. The computation of corresponding maximum value of shunt resistance across the real part of steady-state equivalent stator impedance of motor under minimum mechanical load condition, based on computer simulation result is given as-

$$
\text { Rsh_max }=608.1699 \Omega
$$

Similarly, it is reasonable to assume ninety five percent $(95 \%)$ reduction in real part of equivalent steady-state stator impedance per phase at minimum mechanical load to simulate the finite maximum state of degradation of stator groundwall insulation. The computation of corresponding minimum value of shunt resistance across the real part of steady-state equivalent stator impedance of motor under minimum mechanical load condition, based on computer simulation result is given as-

$$
\text { Rsh_min }=1.6847 \Omega
$$

Forgoing results focus the range of maximum to minimum shunt resistances, which simulate the minimum to maximum percentage degradation of stator groundwall insulation. This range is subdivided into large number of samples to simulate the partial degrees of degradation of stator groundwall insulation. The ' $\mathrm{m}$ ' numbers of samples of specific values of shunt resistances with an equal-space interval of 5\% degradation as represented in equation (6) are computed to simulate the equal-space uniform distribution of percentage degradation over the entire range from minimum finite value of $5 \%$ to maximum finite value of $95 \%$.

$$
\mathrm{G}=\left[\mathrm{Rsh} \_\mathrm{xd}\right]_{1 \mathrm{xm}}=(1 \mathrm{xm}) \text { dimension shunt resistance matrix. }
$$

The values of motor variables, which are modeling the ' $\mathrm{m}$ ' number of equal -space states in between the five $(5 \%)$ and ninety-five $(95 \%)$ percent of degradation of stator groundwall insulation, are computed in form of matrix with - $\left(\begin{array}{lll}1 & \mathrm{x} \mathrm{m}\end{array}\right)$ dimension. The corresponding values of motor variables would simulate the finite range of percentage degradation of stator groundwall insulation per-phase. The simulation results of computation of motor variables like- absolute value of equivalent motor-impedance per phase referred to stator in the form of matrix-[Zseq1_im_xd] $]_{1 \mathrm{xm}}$ in $\Omega$, absolute value of stator current per phase in the form of matrix-[Ias_nl_xd] $]_{1 x m}$ in amps; and motor power-factor in the form of matrix-[pf_nl_xd $]_{1 x m}$ at minimum mechanical load with some finite equal-space intermediate 'xd-percent' model of degradation of stator groundwall insulation of respective phases are as shown in Table 2 .

\subsection{Computation of Stator Current Data Pattern Based on Park's Current Transformation Model}

The park's vector pattern learning approach has been successfully applied in the fault diagnosis of ac induction motor drive [5, 6]. In this investigation, the same approach is applied for the evaluation of different state of percentage degradation of stator groundwall insulation for respective phases of stator winding of induction motor. The Current Park's transformation model herewith simplifies the mathematical model of induction motor on account of its unique property of eliminating all time varying inductances.

Table 2. Simulation Results For $M=19$ Number of Samples of Equal-Space Percentage Degradation of Stator Groundwall Insulation

\begin{tabular}{|c|c|c|c|c|}
\hline per_xd & Rsh_xd & Zseq1_im_xd & Ias_nl_xd & pf_nl_xd \\
\hline 5 & 608.1699 & 35.3853 & 6.7712 & 0.8594 \\
\hline 10 & 288.0805 & 34.0198 & 7.043 & 0.8468 \\
\hline 15 & 181.384 & 32.6756 & 7.3327 & 0.8327 \\
\hline 20 & 128.0358 & 31.3555 & 7.6414 & 0.8167 \\
\hline 25 & 96.0268 & 30.0627 & 7.97 & 0.7986 \\
\hline 30 & 74.6875 & 28.8008 & 8.3192 & 0.778 \\
\hline 35 & 59.4452 & 27.574 & 8.6894 & 0.7545 \\
\hline 40 & 48.0134 & 26.3873 & 9.0801 & 0.7278 \\
\hline 45 & 39.122 & 25.2463 & 9.4905 & 0.6973 \\
\hline 50 & 32.0089 & 24.1575 & 9.9182 & 0.6625 \\
\hline 55 & 26.1891 & 23.1283 & 10.3596 & 0.6228 \\
\hline 60 & 21.3393 & 22.167 & 10.8089 & 0.5776 \\
\hline 65 & 17.2356 & 21.2827 & 11.258 & 0.5264 \\
\hline 70 & 13.7181 & 20.4855 & 11.6961 & 0.4688 \\
\hline 75 & 10.6696 & 19.7858 & 12.1097 & 0.4044 \\
\hline 80 & 8.0022 & 19.1944 & 12.4828 & 0.3335 \\
\hline 85 & 5.6486 & 18.7215 & 12.7981 & 0.2565 \\
\hline 90 & 3.5565 & 18.3763 & 13.0385 & 0.1742 \\
\hline 95 & 1.6847 & 18.166 & 13.1895 & 0.0881 \\
\hline
\end{tabular}

As a function of mains phase variables $\left(i_{a}, i_{b}, i_{c}\right)$ the Current Park's vector components $\left(i_{d}, i_{q}\right)$ are-

$$
\left\{\begin{array}{c}
i_{d}=\sqrt{\frac{2}{3}} i_{a}-\frac{1}{\sqrt{6}} i_{b}-\frac{1}{\sqrt{6}} i_{c} \\
i_{q}=\frac{1}{\sqrt{2}} i_{b}-\frac{1}{\sqrt{2}} i_{c}
\end{array}\right.
$$

Under ideal conditions, three phase currents lead to a Current Park's vector with the following components.

$$
\left\{\begin{array}{l}
i_{d}=\frac{\sqrt{6}}{2} I \sin \varpi t \\
i_{q}=\frac{\sqrt{6}}{2} I \sin \left(\varpi t-\frac{\pi}{2}\right)
\end{array}\right.
$$


Where; I - Maximum value of the supply phase current;

$\omega$-Supply frequency;

$\mathrm{t}$ - Time variable.

The percentage of degradation of stator groundwall insulation perphase is determined on the basis of unbalance in stator phase currents. The degree of unbalance in three-phase stator current is determined with respect to healthy state viz. zero-percentage $(0 \%)$ of degradation of stator groundwall insulation. The complete set of state of degradation over the range of zero-percent $(0 \%)$ to some finite maximum model of ninety-five percent $(95 \%)$ of degradation is determined by including the zero-percent $(0 \%)$ frame of reference to the rest of the set of ' $\mathrm{m}=19$ ' number of samples of percentage degradation (as specified in Table 2) of stator groundwall insulation for a particular phase. The simple computer program is designed to compute the number of permutation and combinations of these percentage degradation samples viz. ' $\mathrm{m}+1=20$ ' to model ' 8000 ' number of unique combinations. Each one of these ' 8000 ' combinations are simulating the specific variation in the state of percentage degradation of stator groundwall insulation for the respective phases viz. a, b and $\mathrm{c}$ of stator winding of three-phase induction motor under test. The few of these combinations comprise of equivalent motor impedance per-phase referred to stator for motor operating at minimum mechanical load, which are simulating the end limit conditions of the state of percentage degradation of stator groundwall insulation of respective phases, are listed in Table 3. The motor machine variables viz. $Z_{a}, Z_{b}$ and $Z_{c}$ represents equivalent motor impedance per-phase referred to stator in $\operatorname{ohms}(\Omega)$ for motor operating at minimum mechanical load for all the respective phases viz. a, b and c.

Ideal condition refers to zero-percent $(0 \%)$ state of percentage of degradation of stator groundwall insulation of the respective phases. The associated motor variables for this state of reference are represented by the combination no. 1 in Table-3. First, the respective three-phase stator currents viz. $\mathrm{I}_{\mathrm{a}}, \mathrm{I}_{\mathrm{b}}$ and $\mathrm{I}_{\mathrm{c}}$ in amps; are computed and then on the basis of three to two-phase transformation model its Current Park's vector pattern is determined. The Current Park's vector representation is a circular pattern centered at the origin of the coordinate-axis as illustrated by Figure 4.

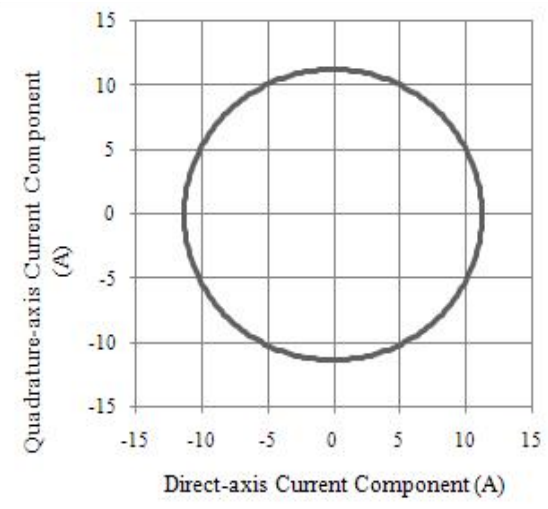

Figure 4. Reference Circular Current Park's Vector Pattern to Simulate Zero-Percent State of Degradation.
The current park's vector pattern as shown in Figure 4; is in the form of circle with radius $(\mathrm{R})=11.268 \mathrm{amps}$, and eccentricity $(\mathrm{C})$ $=0$. The circular current vector pattern with the length of major and minor axis (22.5729A.) is same as double of its radius is considered as a reference current vector pattern to represent healthy state of stator groundwall insulation of the respective phases. This reference current circular pattern contribute the phase-shift displacement of ' $\theta=0^{\circ}$ ' with respect to direct-axis current component vector directed along positive horizontal $\mathrm{x}$ axis. It represents zero-percent state of groundwall insulation degradation in all the respective three phases.

Table 3. Combinations of Equivalent Motor Impedances to Simulate Different State of Percentage Degradation of Stator Groundwall Insulation

\begin{tabular}{|c|c|c|c|c|}
\hline No. & $\begin{array}{l}Z_{a} \\
(\Omega)\end{array}$ & $\begin{array}{l}Z_{b} \\
(\Omega)\end{array}$ & $\begin{array}{l}Z_{c} \\
(\Omega)\end{array}$ & $\begin{array}{l}\text { Percentage of State } \\
\text { of Degradation in } \\
\text { Respective Phases }\end{array}$ \\
\hline 1 & 36.7698 & 36.7698 & 36.7698 & $\begin{array}{c}\text { Minimum-0\% } \\
\text { in all }(\mathrm{a}, \mathrm{b} \text { and } \mathrm{c})\end{array}$ \\
\hline 6 & 36.7698 & 36.7698 & 30.0627 & $\begin{array}{l}\text { Minimum- } 0 \% \text { in a, b. } \\
25 \% \text {-in c. }\end{array}$ \\
\hline 20 & 36.7698 & 36.7698 & 18.166 & $\begin{array}{l}\text { Minimum- } 0 \% \text { in } \mathrm{a}, \mathrm{b} . \\
\text { Maximum- } 95 \% \text {-in c. }\end{array}$ \\
\hline 1264 & 32.6756 & 32.6756 & 32.6756 & $15 \%$ in all $(a, b, c)$ \\
\hline 101 & 36.7698 & 30.0627 & 36.7698 & $\begin{array}{c}\text { Minimum- } 0 \% \text { in a, c. } \\
25 \% \text {-in b. }\end{array}$ \\
\hline 381 & 36.7698 & 18.166 & 36.7698 & $\begin{array}{l}\text { Minimum- } 0 \% \text { in a, c. } \\
\text { Maximum- } 95 \% \text {-in b. }\end{array}$ \\
\hline 2001 & 30.0627 & 36.7698 & 36.7698 & $\begin{array}{l}\text { Minimum- } 0 \% \text { in b, c. } \\
25 \% \text {-in a. }\end{array}$ \\
\hline 7601 & 18.166 & 36.7698 & 36.7698 & $\begin{array}{l}\text { Minimum- } 0 \% \text { in b, c. } \\
\text { Maximum- } 95 \% \text {-in a. }\end{array}$ \\
\hline 43 & 36.7698 & 34.0198 & 34.0198 & $\begin{array}{c}\text { Minimum- } 0 \% \text { in a. } \\
10 \% \text {-in b, c. }\end{array}$ \\
\hline 106 & 36.7698 & 30.0627 & 30.0627 & $\begin{array}{l}\text { Minimum- } 0 \% \text { in a. } \\
25 \% \text {-in b, c. }\end{array}$ \\
\hline 211 & 36.7698 & 24.1575 & 24.1575 & $\begin{array}{l}\text { Minimum- } 0 \% \text { in a. } \\
50 \% \text {-in b, c. }\end{array}$ \\
\hline 400 & 36.7698 & 18.166 & 18.166 & $\begin{array}{l}\text { Minimum- } 0 \% \text { in a. } \\
\text { Max.- } 95 \% \text {-in b, c. }\end{array}$ \\
\hline 5053 & 22.167 & 22.167 & 22.167 & $60 \%$ in all $(a, b, c)$ \\
\hline 1261 & 32.6756 & 32.6756 & 36.7698 & $\begin{array}{l}\text { Minimum- } 0 \% \text { in c. } \\
15 \% \text {-in a, b. }\end{array}$ \\
\hline 7981 & 18.166 & 18.166 & 36.7698 & $\begin{array}{l}\text { Minimum- } 0 \% \text { in c. } \\
\text { Max.- } 95 \% \text {-in a, b. }\end{array}$ \\
\hline 1605 & 31.3555 & 36.7698 & 31.3555 & $\begin{array}{l}\text { Minimum- } 0 \% \text { in b. } \\
20 \% \text {-in a, c. }\end{array}$ \\
\hline 7620 & 18.166 & 36.7698 & 18.166 & $\begin{array}{l}\text { Minimum- } 0 \% \text { in b. } \\
\text { Max.- } 95 \% \text {-in a, c. }\end{array}$ \\
\hline 220 & 36.7698 & 24.1575 & 18.166 & $\begin{array}{l}\text { Min. }-0 \% \text { in a, } \\
50 \%-\text { in b, } \\
\text { Max. }-95 \% \text { in c. }\end{array}$ \\
\hline 7611 & 18.166 & 36.7698 & 24.1575 & $\begin{array}{l}\text { Max. }-95 \% \text { in } a, \\
\text { Min.- } 0 \% \text { in b, } \\
50 \% \text { in c. }\end{array}$ \\
\hline 4381 & 24.1575 & 18.166 & 36.7698 & $\begin{array}{c}50 \% \text { in a, } \\
\text { Max. }-95 \% \text { in b, } \\
\text { Min. }-0 \% \text { in c. }\end{array}$ \\
\hline 8000 & 18.166 & 18.166 & 18.166 & $\begin{array}{l}\text { Maximum.:95 \% } \\
\text { in all }(\mathrm{a}, \mathrm{b} \text { and } \mathrm{c})\end{array}$ \\
\hline
\end{tabular}




\section{CLASSIFICATION OF PERCENTAGE DEGRADATION BASED ON CURRENT} PARK'S VECTOR PATTERN

The computer program is designed to determine the Current Park's vector data patterns for the number of combinations of steady-state equivalent motor impedances per-phase referred to stator of respective phases as specified in Table 3 . These combinations are in fact simulating the different state of percentage degradation of stator groundwall insulation of respective phases. The computer program is further designed to extract the features of Current Park's vector data pattern. The classification of various states of percentage degradation is done on the basis of comparison of extracted parameter features of various Current Park's vector data pattern with respect to the reference pattern as shown in Figure 4. The computer simulation results further implies that each one of the current park's vector data pattern is unique in representing the degree of unbalance in three-phase stator current on account of specific state of degradation of stator groundwall insulation of respective phases.

The Table 4; lists the computer simulation results, which primarily focus on the extracted parameter features like- radius (R) in amps; length of major and minor axis $\left(\mathrm{M}_{\mathrm{a}}, \mathrm{M}_{\mathrm{b}}\right)$ in amps; phase-shift angular displacement $\left(\theta^{\circ}\right)$ and eccentricity $(\mathrm{C})$ of Current Park's vector data patterns for the numbers of specific combinations listed in Table 3 . The computer simulation results further provide the RMS values of three-phase balance and/or unbalance stator currents of respective phases viz. Ia, Ib and Ic in amps. The representation of the classification of various states, based on illustration of Current Park's vector data patterns is as follows-

\subsection{Equal Percentage Degradation in all the Three-Phases of Stator Winding}

The Current Park's vector data patterns for the simulation combination no. '1264',' 5053' and '8000' (refer Table 3 and Table 4), which is simulating ' $15 \%$ ', ' $60 \%$ ' and maximum of ' $95 \%$ ' of equal state of percentage degradation in all the three respective phases viz. a, b and $\mathrm{c}$ is illustrated by Figure 5. The Current Park's vector data patterns are in circular form with centre at origin and of eccentricity approximately close to zero. The variation is observed with respect to reference circular current vector pattern as shown in Figure 4.

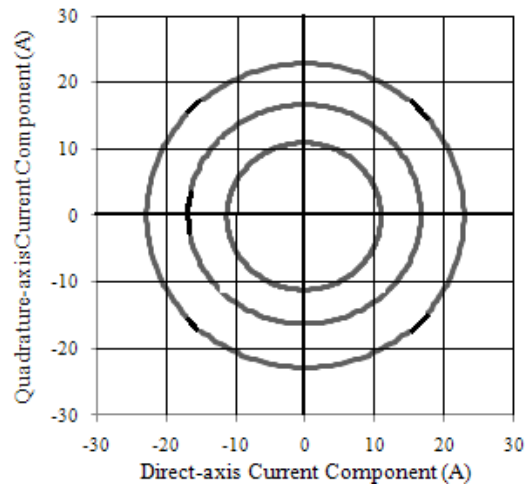

Figure 5. Current Park's Vector Pattern to Simulate Various States of Equal Percentage of Degradation in All Phases

\subsection{Variation in Percentage Degradation in} Phase-C from Minimum to Maximum Value and Healthy State for Phase-A and Phase-B.

The Current Park's vector data patterns for the simulation combination no. ' 6 ' and ' 20 ' (refer Table 3 and Table 4), which is simulating ' $25 \%$ ' and maximum of ' $95 \%$ ' of state of percentage degradation respectively in 'phase-c' and healthy state of stator groundwall insulation viz. zero-percent $(0 \%)$ degradation of stator groundwall insulation for 'phase-a' and 'phase-b' is illustrated by Figure 6. The presence of some finite percentage of degradation of stator groundwall insulation in 'phase-c' introduce the change in the shape of Current Parks vector pattern from circular to elliptical form.

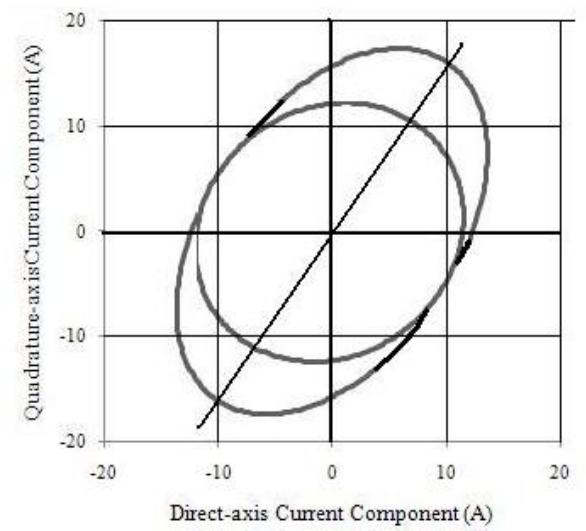

Figure 6. Current Park's Vector Pattern to Simulate 25\% and Maximum $95 \%$ of State of Degradation in Phase-C and Healthy State in Phase-A and Phase-B

\subsection{Variation in Percentage Degradation in} Phase-B from Minimum to Maximum Value and Healthy State for Phase-A and Phase-C

The Current Park's vector data patterns for the simulation combination no. '101' and '381' (refer Table 3 and Table 4), which is simulating ' $25 \%$ ' and maximum of ' $95 \%$ ' of state of percentage degradation respectively in 'phase-b' and healthy state of stator groundwall insulation for 'phase-a' and 'phase-c' is illustrated by Figure 7 .

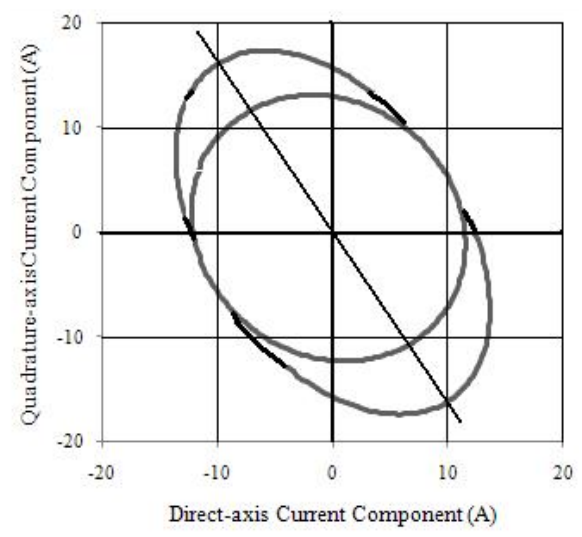

Figure 7. Current Park's Vector Pattern to Simulate 25\% and Maximum $95 \%$ of State of Degradation in Phase-B and Healthy State in Phase-A and Phase-C 


\subsection{Variation in Percentage Degradation in} Phase-A from Minimum to Maximum Value and Healthy State for Phase-B and Phase-C.

The Current Park's vector data patterns for the simulation combination no. '2001' and '7601' (refer Table 3 and Table 4 ), which is simulating ' $25 \%$ ' and maximum of ' $95 \%$ ' of state of percentage degradation respectively in 'phase-a' and healthy state of stator groundwall insulation for 'phaseb' and 'phase-c' is illustrated by Figure 8 .

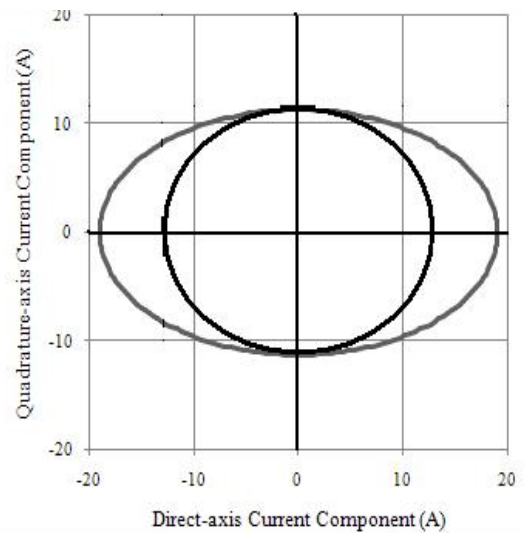

Figure 8. Current Park's Vector Pattern to Simulate 25\% and Maximum $95 \%$ of State of Degradation in Phase-A and Healthy State in Phase-B and Phase-C

\subsection{Variation in Percentage Degradation in} Phase- $B$ and $C$ from Minimum to Maximum Value and Healthy State for Phase-A.

The Current Park's vector data patterns for the simulation combination no. '43', '106', '211'and '400' (refer Table 3 and Table 4), which is simulating ' $10 \%$ ', ' $25 \%$ ', $50 \%$ ' and maximum of ' $95 \%$ ' of state of percentage degradation respectively in 'phase-b' and 'phase-c' and healthy state of stator groundwall insulation for 'phase-a' only is illustrated by Figure 9. The deformation in an elliptical form with the variation in percentage degradation in 'phase-b' and 'phase-c' are observed with respect to reference circular current vector pattern as shown in Figure 4.

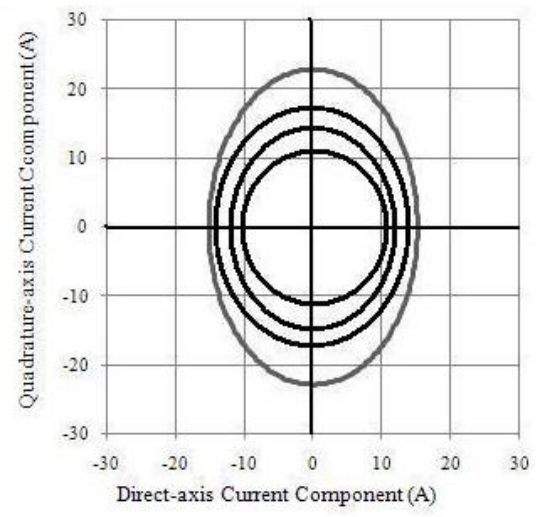

Figure 9. Current Park's Vector Pattern to Simulate $10 \%$ to $95 \%$ Maximum State of Degradation in Phase-B and Phase-C and Healthy State of Stator Groundwall Insulation in Phase-A

\subsection{Variation in Percentage Degradation in} Phase-A and B from Minimum to Maximum Value and Healthy State for Phase-C.

The Current Park's vector data patterns for the simulation combination no. '1261'and '7981' (refer Table 3 and Table 4), which is simulating ' $15 \%$ ', and maximum of ' $95 \%$ ' of state of percentage degradation respectively in 'phase-a' and 'phase-b' and healthy state of stator groundwall insulation for 'phase-c' only is illustrated by Figure 10.

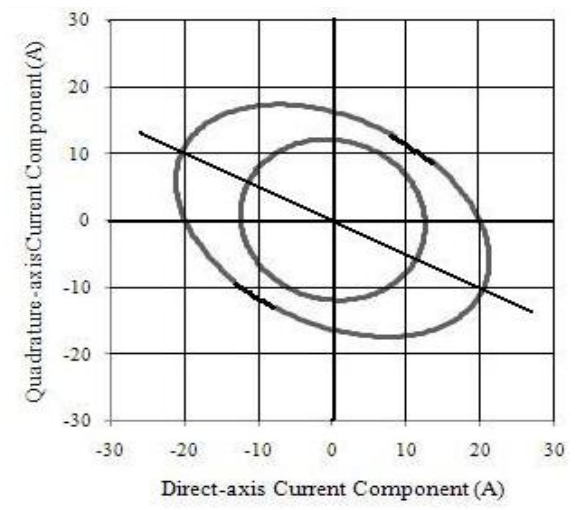

Figure 10. Current Park's Vector Pattern to Simulate 15\% to $95 \%$ Maximum State of Degradation in Phase-B and Phase-C and Healthy State of Stator Groundwall Insulation in Phase-A

\subsection{Variation in Percentage Degradation in} Phase- $\mathrm{A}$ and $\mathrm{C}$ from Minimum to Maximum Value and Healthy State for Phase-B.

The Current Park's vector data patterns for the simulation combination no. ' 1605 ' and ' 7620 ' (refer Table 3 and 4), which is simulating ' $20 \%$ ', and maximum of ' $95 \%$ ' of state of percentage degradation respectively in 'phase-a' and 'phase-c' and healthy state of stator groundwall insulation for 'phase-b' only is illustrated by Figure 11 .

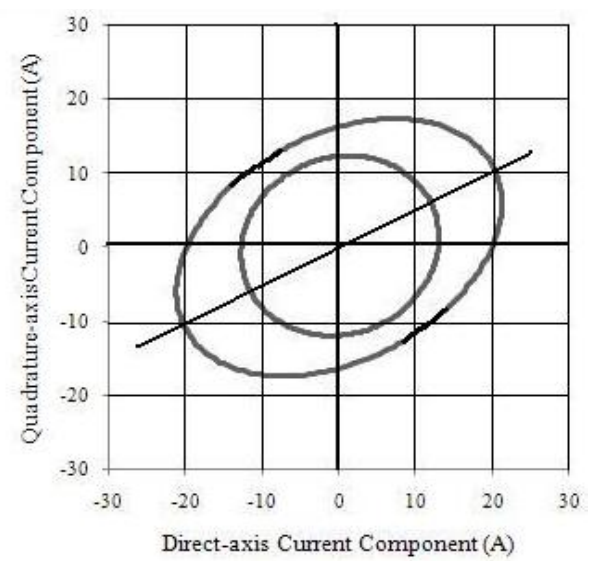

Figure 11. Current Park's Vector Pattern to Simulate 20\% to $95 \%$ Maximum State of Degradation in Phase-A and Phase-C and Healthy State of Stator Groundwall Insulation in Phase-B 
Table 4. Parameter Features of Current Park's Vector Data Patterns

\begin{tabular}{|c|c|c|c|c|c|c|c|c|c|c|c|}
\hline No. & $\begin{array}{l}Z_{\mathrm{a}} \\
(\Omega)\end{array}$ & $\begin{array}{c}Z_{b} \\
(\Omega)\end{array}$ & $\begin{array}{c}\mathbf{Z}_{\mathrm{c}} \\
(\boldsymbol{\Omega})\end{array}$ & $\begin{array}{c}\mathbf{I}_{\mathrm{a}} \\
(\mathbf{A})\end{array}$ & $\begin{array}{c}\mathbf{I}_{\mathrm{b}} \\
(\mathbf{A})\end{array}$ & $\begin{array}{c}\mathbf{I}_{\mathrm{c}} \\
(\mathbf{A})\end{array}$ & $\begin{array}{c}\text { Major } \\
\text { axis- } \\
\mathbf{M}_{\mathrm{a}} \text { (A) }\end{array}$ & $\begin{array}{c}\text { Minor } \\
\text { axis- } \\
\text { M }_{\mathrm{b}} \text { (A) }\end{array}$ & $\begin{array}{c}\text { Phase } \\
\text { shift - } \\
\left(\theta^{\circ}\right)\end{array}$ & $\begin{array}{c}\text { Eccentric } \\
\text {-city } \\
(\mathbf{C})\end{array}$ & $\begin{array}{l}\text { Type of } \\
\text { Pattern }\end{array}$ \\
\hline 1 & 36.7698 & 36.7698 & 36.7698 & 6.5162 & 6.5162 & 6.5162 & 22.5729 & 22.5729 & 0 & 0 & Circular \\
\hline 6 & 36.7698 & 36.7698 & 30.0627 & 6.5162 & 6.5162 & 7.97 & 25.9299 & 22.5733 & 59.4777 & 0.4921 & Elliptic \\
\hline 20 & 36.7698 & 36.7698 & 18.166 & 6.5162 & 6.5162 & 13.1895 & 37.9827 & 22.5752 & 59.6434 & 0.8042 & Elliptic \\
\hline 1264 & 32.6756 & 32.6756 & 32.6756 & 7.3327 & 7.3327 & 7.3327 & 25.4012 & 25.4012 & 0 & 0 & Circular \\
\hline 101 & 36.7698 & 30.0627 & 36.7698 & 6.5162 & 7.97 & 6.5162 & 25.9299 & 22.5733 & -59.4777 & 0.4921 & Elliptic \\
\hline 381 & 36.7698 & 18.166 & 36.7698 & 6.5162 & 13.1895 & 6.5162 & 37.9827 & 22.5752 & -59.6434 & 0.8042 & Elliptic \\
\hline 2527 & 28.8008 & 28.8008 & 28.8008 & 8.3192 & 8.3192 & 8.3192 & 28.8187 & 28.8187 & 0 & 0 & Circular \\
\hline 2001 & 30.0627 & 36.7698 & 36.7698 & 7.97 & 6.5162 & 6.5162 & 25.9303 & 22.5729 & 180.0 & 0.4921 & Elliptic \\
\hline 7601 & 18.166 & 36.7698 & 36.7698 & 13.1895 & 6.5162 & 6.5162 & 37.9841 & 22.5729 & 180.0 & 0.8043 & Elliptic \\
\hline 43 & 36.7698 & 34.0198 & 34.0198 & 6.5162 & 7.043 & 7.043 & 24.3976 & 23.1811 & -90 & 0.3118 & Elliptic \\
\hline 106 & 36.7698 & 30.0627 & 30.0627 & 6.5162 & 7.97 & 7.97 & 27.609 & 24.2516 & -90 & 0.4779 & Elliptic \\
\hline 211 & 36.7698 & 24.1575 & 24.1575 & 6.5162 & 9.9182 & 9.9182 & 34.3578 & 26.5012 & -90 & 0.6364 & Elliptic \\
\hline 400 & 36.7698 & 18.166 & 18.166 & 6.5162 & 13.1895 & 13.1895 & 45.6897 & 30.2785 & -90 & 0.7489 & Elliptic \\
\hline 5053 & 22.167 & 22.167 & 22.167 & 10.8089 & 10.8089 & 10.8089 & 37.4431 & 37.4431 & 0 & 0 & Circular \\
\hline 1261 & 32.6756 & 32.6756 & 36.7698 & 7.3327 & 7.3327 & 6.5162 & 25.401 & 23.5159 & -30.5555 & 0.378 & Elliptic \\
\hline 7981 & 18.166 & 18.166 & 36.7698 & 13.1895 & 13.1895 & 6.5162 & 45.6882 & 30.2806 & -30.3976 & 0.7488 & Elliptic \\
\hline 1204 & 32.6756 & 36.7698 & 32.6756 & 7.3327 & 6.5162 & 7.3327 & 25.401 & 23.5159 & 30.5555 & 0.378 & Elliptic \\
\hline 1605 & 31.3555 & 36.7698 & 31.3555 & 7.6414 & 6.5162 & 7.6414 & 26.4703 & 23.8724 & 30.5411 & 0.432 & Elliptic \\
\hline 7620 & 18.166 & 36.7698 & 18.166 & 13.1895 & 6.5162 & 13.1895 & 45.6882 & 30.2806 & 30.3976 & 0.7488 & Elliptic \\
\hline 220 & 36.7698 & 24.1575 & 18.166 & 6.5162 & 9.9182 & 13.1895 & 40.8802 & 27.5335 & 75.5099 & 0.7392 & Elliptic \\
\hline 7611 & 18.166 & 36.7698 & 24.1575 & 13.1895 & 6.5162 & 9.9182 & 40.8778 & 27.5370 & 15.9141 & 0.7391 & Elliptic \\
\hline 4381 & 24.1575 & 18.166 & 36.7698 & 9.9182 & 13.1895 & 6.5162 & 40.8801 & 27.5337 & -44.8942 & 0.7392 & Elliptic \\
\hline 8000 & 18.166 & 18.166 & 18.166 & 13.1895 & 13.1895 & 13.1895 & 45.6897 & 45.6897 & 0 & 0 & Circular \\
\hline
\end{tabular}

4.8 Minimum to Maximum Value of Variation in Percentage Degradation in Phase$A, B$ and $C$

The Current Park's vector data pattern for the simulation combination no. '220','7611, and '4381' (refer Table 3 and Table 4), which is simulating healthy state viz. minimum -zeropercentage $(0 \%)$, ' $50 \%$ ' of percentage degradation and maximum of $95 \%$ of percentage degradation of stator groundwall insulation degradation in 'phase-a', 'phase-b' and in 'phase-c' respectively is illustrated by Figure 12 .

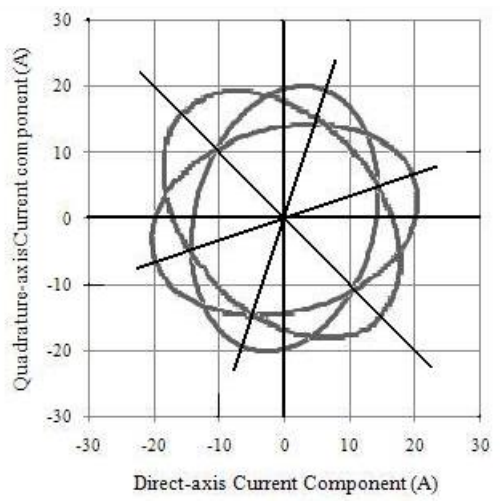

Figure 12. Current Park's Vector Pattern to Simulate Minimum to Maximum State of Stator Groundwall Insulation Degradation in Phase-A, B and C
The similar order of variation in the state of degradation of groundwall stator insulation in respective phases viz. a, b and c, leads to the same kind of deformation of Current Park's vector data pattern from circular form into an elliptical form with the same variation in the length of major -and in the minor-axes as shown in Figure 12.

\section{DISCUSSION OF RESULTS}

In case of equal percentage degradation in all the three phases of stator winding as shown in Figure 5; the Current Park's vector data patterns are in circular form with centre at origin and of eccentricity approximately close to zero. The length of major $\left(\mathrm{M}_{\mathrm{a}}\right)$ and minor axis $\left(\mathrm{M}_{\mathrm{b}}\right)$ of circular data pattern increases from ' 25.4012 ' A. to ' 45.6897 ' A. The variation is observed with respect to reference circular current vector pattern as shown in Figure 4 . The change in the angular phase-shift displacement $\left(\theta^{\circ}\right)$ is marginal and approximately equal to $0^{\circ}$ with respect to positive $\mathrm{x}$-axis of 'dq' coordinate plane.

As shown in Figure 6; the presence of some finite percentage of degradation of stator groundwall insulation in 'phase-c' introduce the change in the shape of Current Parks vector pattern from circular to elliptical form. The deformation in an elliptical form changes with the variation in percentage degradation in phase-c. The observed variation in the length of major axis (25.9299 A. to 37.9827 A.) is significant but in minor-axis (22.5723 A. to 22.5752 A.) is marginal with respect to reference circular current pattern as shown in Figure 4. The change in the percentage degradation of stator groundwall insulation in 'phase-c' from $25 \%$ 
to maximum value of $95 \%$ leads to an increase in the deformation in elliptical pattern with the rise in the observed value of eccentricity ( 0.4921 to 0.8042$)$ towards unity. The phase-shift angular displacement $\left(\theta^{\circ}\right)$ oscillates approximately at around ' $\theta=$ $+60^{\circ}$, with respect to positive $\mathrm{x}$ - axis with the change in the percentage degradation between $5 \%$ viz. reasonably healthy state and maximum- $95 \%$ viz. worst case of stator groundwall insulation degradation in phase-c.

The changes observed in the deformation of an elliptical pattern with the variation in the percentage degradation in 'phase-b' are exactly the same like in 'phase-c'. However, As shown in Figure 7; The phase-shift angular displacement $\left(\theta^{\circ}\right)$ oscillates approximately at around ' $\theta=-60^{\circ}$ ' with respect to positive $\mathrm{x}$-axis with the change in the percentage degradation between $5 \%$ viz. reasonably healthy state and maximum- $95 \%$ viz. worst case of stator groundwall insulation degradation in phase-b. The changes observed in the deformation of an elliptical pattern with the variation in percentage degradation in 'phase-a' are exactly the same like in 'phase-c' and phase-'b'. However, As shown in Figure 8; The phase-shift angular displacement $\left(\theta^{\circ}\right)$ remain constant at $\theta=180^{\circ}$ with respect to positive $\mathrm{x}$-axis due to change in the percentage degradation between ' $5 \%$ ' viz. reasonably healthy state and maximum- ' $95 \%$ ' viz. worst case of stator groundwall insulation degradation in phase-a.

As shown in Figure 9; the presence of some finite percentage of degradation of stator groundwall insulation in 'phase-b' and 'phase-c' introduce the change in the shape of Current Park's vector pattern from circular to elliptical form. The deformation in an elliptical form changes with the variation in percentage degradation in 'phase-c' and 'phase-b'. The observed variations in the length of major axis (24.3976 A. to 45.6897A) and in minoraxis (23.1811A. to 30.2785A.) are both significant with respect to reference circular current vector pattern as shown in Figure 4 . The change in the percentage degradation of stator groundwall insulation in 'phase-b' and 'phase-c' from $10 \%$ to maximum value of $95 \%$ leads to an increase in the deformation in elliptical pattern with the rise in the observed value of eccentricity $(0.3118$ to 0.7489$)$ towards unity. The phase-shift angular displacement $\left(\theta^{\circ}\right)$ remain constant at ' $\theta=-90^{\circ}$ ' with respect to positive $\mathrm{x}$-axis of dq-coordinate plane. It is not affected on account of change in the percentage degradation between $5 \%$ viz. reasonably healthy state and maximum- $95 \%$ viz. worst case of stator groundwall insulation degradation in 'phase-b' and 'phase-c'.

The changes observed in the deformation of an elliptical pattern with the variation in percentage degradation in 'phase-a' and 'phase-b' are exactly the same like in 'phase-b' and 'phase-c'. However, As shown in Figure 10; The phase-shift angular displacement $\left(\theta^{\circ}\right)$ oscillates approximately at around ' $\theta=-30^{\circ}$ ' with respect to positive $\mathrm{x}$-axis of dq-coordinate plane on account of change in the percentage degradation between $5 \%$ viz. reasonably healthy state and maximum- $95 \%$ viz. worst case of stator groundwall insulation degradation in 'phase-a' and 'phaseb'. The changes observed in the deformation of an elliptical pattern with the variation in percentage degradation in 'phase-a' and 'phase-c' are exactly the same like in 'phase-a' and 'phase-b'. However, As shown in Figure 11; The phase-shift angular displacement $\left(\theta^{\circ}\right)$ oscillates approximately at around ' $\theta=+30^{\circ}$ ' with respect to positive $\mathrm{x}$-axis of dq-coordinate plane on account of change in the percentage degradation between $5 \%$ viz. reasonably healthy state and maximum- $95 \%$ viz. worst case of stator groundwall insulation degradation in 'phase-a' and 'phasec'.

As shown in Figure 12; one of the Current Park's vector pattern which is simulating healthy state viz. minimum -zero-percentage $(0 \%)$, ' $50 \%$ ' of percentage degradation and maximum of ' $95 \%$ ' of percentage degradation of stator groundwall insulation degradation in phase ' $a$ ', phase-b and in phase-c respectively is in an elliptical form with centre at origin and of eccentricity equal to 0.7392 . The length of major $\left(\mathrm{M}_{\mathrm{a}}\right)$ is $40.88 \mathrm{~A}$; and of minor axis $\left(\mathrm{M}_{\mathrm{b}}\right)$ is $27.53 \mathrm{~A}$. The angular phase-shift displacement $(\theta)$ is $75^{\circ}$ approximately in anti-clockwise sense with respect to positive $\mathrm{x}$ axis. The rise in the length of major $\left(\mathrm{M}_{\mathrm{a}}\right)$ is $81.1 \%$ and of minor axis $\left(\mathrm{M}_{\mathrm{b}}\right)$ is $21.96 \%$ with respect to reference circular current vector pattern as shown in Figure 4. The similar order of variation in the state of degradation of groundwall stator insulation in respective phases viz. $\mathrm{a}, \mathrm{b}$ and $\mathrm{c}$, leads to the same kind of deformation of Current Park's vector data pattern from circular form $(C=0)$ into an elliptical form $(C=0.7392)$ with the same variation in the length of major -and in the minor-axes as shown in Figure 12. However, the phase-shift angular displacement $\left(\theta^{\circ}\right)$ changes accordingly from $\theta=0^{\circ}$ to $\theta=+75^{\circ}, \theta=+15^{\circ}$, and $\theta=-$ $45^{\circ}$, approximate value with respect to positive $\mathrm{x}$-axis of $\mathrm{dq}$ coordinate axes.

\section{CONCLUSION}

The computer -aided evaluation of percentage degradation of stator groundwall insulation of respective phases based on Park's Current transformation model provide the stator current data patterns over a large scale. Under practical circumstances it is very difficult to obtain the large set of stator current data patterns from the point of view of realization of different state of percentage degradation of stator groundwall insulation. The availability of large set of stator current data patterns emphasizes the need towards the development of the optimal design and efficient performance of artificial neural network classifier. The generated stator current data patterns can be further applied to any suitable artificial neural network (ANN) classifiers for the AIbased fault diagnosis process model to detect the degradation of stator groundwall insulation.

\section{REFERENCES}

[1] H. Nejjari and M. H. Benbouzid, "Monitoring and diagnosis of induction motor faults using current parks vector approach," IEEE Trans. Ind. Applicat., vol.36, no.3, May/June 2000, pp. 730-735.

[2] G. M. Joksimovic and J. Penman, "The detection of interturn short circuits in the stator windings of operating motors," IEEE Trans. Ind. Elect., vol.47, no.5, October 2000, pp. 1078-1084.

[3] G. B. Kliman, W. J. Premerlani, R. A. Koegland D. Hoeweler, "A new approach to on line turn fault detection in AC motors," in Conf. Rec. IEEE -IAS Annu. Meeting, San Diego, CA, 1996, pp. 687-693

[4] Sergio M. A. Cruz and A. J. Marques Cardoso, "Stator winding fault diagnosis in three-phase synchronous and asynchronous motors by the extended parks vector approach," IEEE Trans. Ind. Applicat., vol.37, no.5, Sept./Oct. 2001, pp. 1227-1233. 
[5] S. Nandi and H. A. Toliyat, "Fault diagnosis of electrical machines-A review," in Proc. IEEE Int. Electric Machines and Drives Conf. Seattle.WA, USA, May 9-12 ,1999, pp. 219-221.

[6] G. B. Kliman, W.J. Premerlani, B.Yazici, and R. A. Koegl, "Recent developments in on-line motor diagnostics," Proc. Int. conf. Electrical Machines, vol.1, Istanbul, Turkey, Sept.2-4, 1998, pp. 471-475.

[7] A. J. M. Cardoso et. al., "Inter turn stator winding fault diagnosis in three phase induction motors, by Park's vector approach," IEEE Trans. Energy Conversion, vol.14, no. 3, Sept.1999, pp. 595-598.

[8] A. J. M. Cardoso et al., "Computer aided detection of air gap eccentricity in operating three phase induction motors by Park's vector approach," IEEE Trans. Ind. Applicat., vol.29, Sept. /Oct. 1993, pp. 897-901.
[9] F. C. Trutt et al., "Detection of AC machine winding deterioration using electrically excited vibrations," IEEE Trans. Ind. Applicat., vol.17, no.1, 2001

[10] N. Arthur and J. Penman, "Induction machine conditioning monitoring with higher order spectra," IEEE Trans. Ind. Elect., vol.47, no.5, Oct. 2000, pp. 1031-1041.

[11] F. Filippetti, G. Franceschini, C. Tassoni, and Peter Vas, "Recent developments of induction motor drives fault diagnosis using AI techniques," IEEE Trans. Trans. Ind. Elect., vol.47, no.5, Oct. 2000, pp. 994-1004. 